\title{
Urban Sketchers: o desenho e o olhar
}

\author{
Paulo Henrique Tôrres Valgas ${ }^{1}$
}

DOI 10.20396/eha.vil4.3452

\section{O movimento Urban Sketchers}

Em 2007, o jornalista espanhol Cabi Campanario utilizou a prática de sair às ruas para desenhar a cidade de Seattle, local para onde havia se mudado recentemente, para adaptar-se e conhecer seu novo local de moradia. Desenhos prontos, ele compartilhava-os na rede social Flickr. Essa prática, mesmo que simples, levou-o a criar o blog Urban Sketchers (USk) e a partir daí, o movimento de mesmo nome, que tornou-se um fenômeno mundial e agrupou milhares de pessoas interessadas no desenho in loco e seu compartilhamento em redes sociais. Após mais de dez anos, o Urban Sketchers tem milhares de postagens, grupos organizados em países de todos os continentes, um manifesto que lista as ideias do movimento² e dez simpósios internacionais, que acontecem anualmente $^{3}$. No Brasil, o movimento começou em 2011; em 2014 a cidade de Paraty-R] sediou o simpósio e desde 2016 acontecem encontros nacionais, cujas cidades sede foram Curitiba (2016), São Paulo (2017), Salvador (2018) e Ouro Preto (2019). A imagem 1 é uma fotografia do encontro em Ouro Preto, em junho de 2019, e vemos um participante desenhando a igreja que encontra-se no fundo, sendo também desenhada por outros sketchers, sentados nas cadeiras ou no chão. Vale destacar a característica de sociabilidade (sentam-se próximos uns dos outros) e a atenção dispensada à paisagem (cujos olhos ficam atentos).

\section{Urban Sketchers, o desenho e suas significações}

Uma das questões que envolvem o Urban Sketchers é a apreciação pela prática do desenho, fator que motiva os membros a ingressarem no movimento. O desenho leva os sketchers à uma

\footnotetext{
1 Mestre em Artes Visuais (Udesc), professor de História no IFC- Instituto Federal Catarinense. Artigo produzido pelo edital de pesquisa 202018, com auxílio da bolsista do Ensino Médio Integrado Maria Eduarda Kietzer Senci.

2 1. Nós fazemos desenhos de locação, através da observação direta, seja em ambientes externos ou internos. 2. Nossos desenhos contam histórias do dia a dia, dos lugares em que vivemos, e para onde viajamos. 3. Nossos desenhos são um registro do tempo e do lugar. 4. Nós somos fiéis às cenas que estamos retratando. 5. Nós utilizamos qualquer tipo de técnica e valorizamos cada estilo individual. 6. Nós nos apoiamos e desenhamos juntos. 7. Nós compartilhamos nossos desenhos on-line. 8. Nós mostramos o mundo, um desenho de cada vez.

3 A cidades foram: Portland (2010), Lisboa (2011), Santo Domingo (2012), Barcelona (2013), Paraty (2014), Singapura (2015), Manchester (2016), Chicago (2017), Porto (2018), Amsterdã (2019).
} 
série de experiências, e neste texto se destacam as possibilidades do olhar. A faculdade de ver com mais precisão os locais e o mundo ao nosso redor é uma das potências do ato de desenhar, pois "o desenho educa o olhar, ordena a sensibilidade, exponencia a imaginação criadora e estabelece a possibilidade de comunicação e entendimento [...]"4. Ele pode ser pensado como uma ferramenta e parte de um processo de questionamento, de reflexão, de conhecimento e de compreensão do mundo 5 . Como um ato mental, é um processo complexo"6. Os verbos utilizados por teóricos do desenho são educar, ordenar, comunicar, questionar, conhecer, relacionar, todos vinculados a práticas cognitivas. Isoda ${ }^{7}$ trata o desenho como fenômeno mental, destacando o processo cognitivo, a percepção, o olhar e a memória:

"Usamos o desenho tanto para entender quanto para transmitir o que entendemos. Seja pensando, seja rabiscando, seja observando o mundo, seja vendo o desenho de todas as coisas que nos cercam. [...] Desenho é um processo cognitivo.

No século XIX, Viollet-le-Duc afirmou que o "desenho, propriamente ensinado, é a melhor maneira de desenvolver inteligência e formar julgamento, porque se aprende a ver, e ver é conhecimento. ${ }^{8}$ Ruskin acreditava que o desenho é uma boa maneira de as pessoas estarem atentas às coisas que as rodeiam e que ele as ensina a ver mais do que simplesmente a olhar ${ }^{9}$. Valéry ${ }^{10}$ acredita na potencialidade do desenho para nos fazer ver melhor. Ele afirma que:

Há uma imensa diferença entre ver uma coisa sem o lápis na mão e vê-la desenhando-a. Ou melhor, são duas coisas muito diferentes que vemos. Até mesmo objeto mais familiara nossos olhos torna-se completamente diferente se procurarmos desenhá-lo: percebemos o que ignorávamos, que nunca o tínhamos visto realmente. O olho até então servira apenas de intermediário. Ele nos fazia falar, pensar; guiava nossos passos, nossos movimentos comuns; despertava algumas vezes nossos sentimentos. Até nos arrebatava, mas sempre por efeitos, consequências ou ressonâncias de sua visão, substituindo-a, e portanto abolindo-a no próprio fato de desfrutar dela. Mas o desenho de observação de um objeto confere ao ol ho certo comando alimentado por nossa vontade. Neste caso, deve-se querer para ver e essa visão deliberada tem o desenho como fim e como meio simultaneamente. Não posso tornar precisa minha percepção de uma coisa sem desenhá-la virtualmente, e não posso desenhar essa coisa sem uma atenção voluntária que transforme de forma

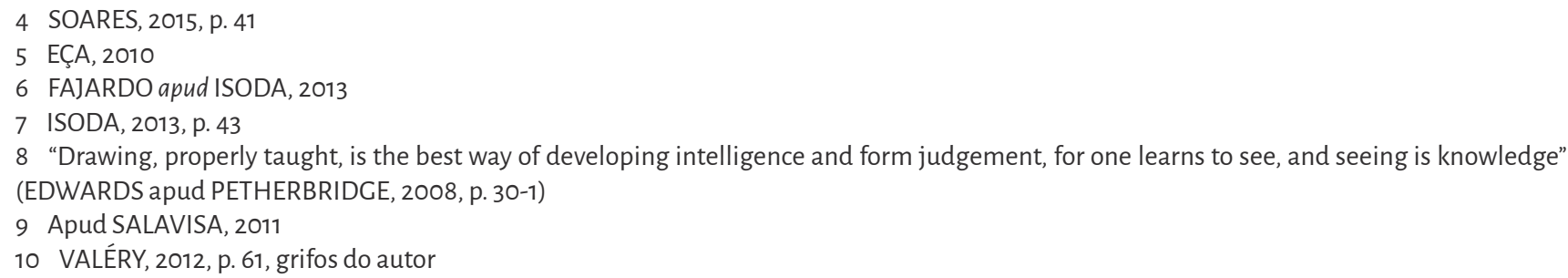


notável o que antes eu acreditava perceber e conhecer bem.

Esta observação atenta é necessário demorar tempo a ver as coisas que se querem desenhar". A palavra draw significa também "chamar a atenção", "atrair" "concluir uma ideia depois de pensar cuidadosamente sobre", "tomar algo para si"12, ideia que coaduna com Edyth Derdyk², para quem essa "qualidade do desenho que é capturar do mundo as coisas, arrastar, trazer para si, que é o drawing, que é aquela capacidade de você absorver e observar do mundo as coisas". Le Corbusier ${ }^{14}$ já defendia que antes de qualquer coisa, desenhar é ver com os olhos, observar, descobrir e aprender a ver: “É necessário desenhar para interiorizar aquilo que foi visto e que ficará então inscrito na nossa memória para toda a vida"15.

A potência do ato de desenhar, ou seja, essa forma de conhecer melhor aquilo que é visto, analisando melhor o derredor, entendendo os processos de percepção e relacionando-se melhor com as cenas e os objetos vistos estão presentes nas postagens e nos relatos de muitos dos urban sketchers. Vamos a alguns exemplos. João Pinheiro ${ }^{16}$, ao desenhar a rua Erva Mularinha (imagem 2), em São Paulo, afirma que essa famosa rua só foi descoberta por ele quando sentou na calçada para desenhá-la. Ele observa seu relevo inclinado e asfalto ruim, com prédios e muros pichados, carros estacionados e pouca movimentação e escreve: "Na rua fico revendo os lugares e remontando acontecimentos passados. Pintaram um muro, derrubaram uma casa, cadê aquela árvore que tinha aqui? aquele bar mudou de dono". O sketcher usa o verbo "remembrando"para expressar seu sentimento de que parece estar "remendando uma colcha de retalhos, ligando pontos de saudade na cabeça, tudo através do desenho". Ele acredita que "desenhar nos dá a possibilidade de parar e refletir, de ver a paisagem, de ver o mundo fora da casa de máquinas, ver como é lá fora". Finalizando, o desenhista cita o poema criado e postado por um amigo no seu blog, cujo título era Remembrança: "O traço captou a melancolia / Que não sei se está no bairro / No traço / Ou nos olhos / De quem via". O sketcher Adriano Mello ${ }^{17}$ escreve sobres suas descobertas:

Tenho prazer em representar o que vejo e os locais onde passo, se chove ou faz sol, o que importa é o momento que desligo de tudo e encontro prazer em desenhar. Por enquanto

\footnotetext{
11 TAVARES, 2011

ISODA, 2003, p. 22-3

DERDYK apud ISODA, 2013, p. 86

CORBUSIER apud GORDO, 2014, p. 89

5 CORBUSIER, 1968 apud SOARES, 2015, p. 11

16 PINHEIRO, 2011

17 MELLO, 2014
} 


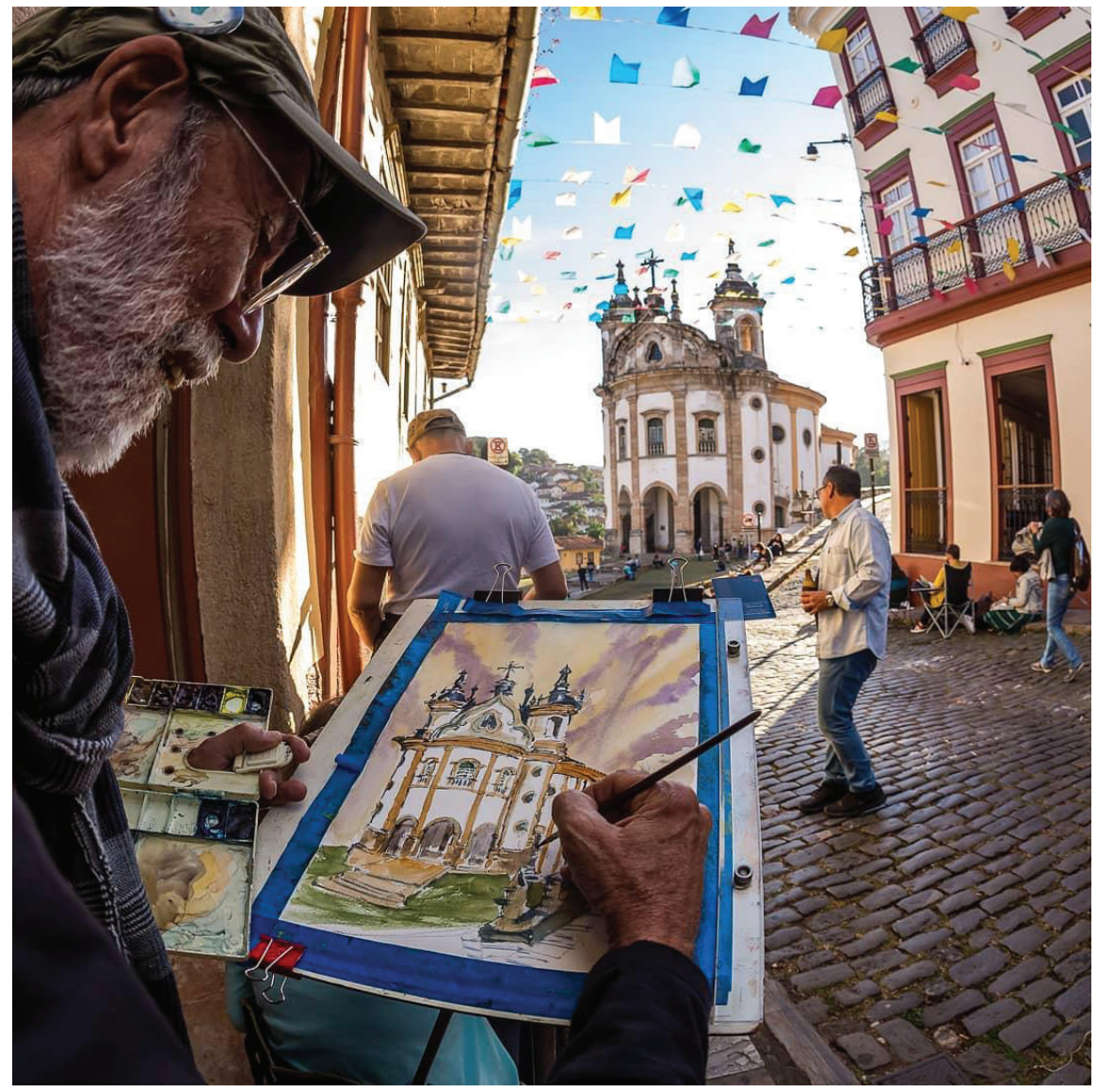

[Figura 1]

Encontro Urban Sketchers em Ouro Preto. Fotografia de Nelson Polzin. 2019.

Disponível em: <.https://hype-hub. com/author/urban-sketchers-brasil/17252634> Acesso em: 01 out. 2019.

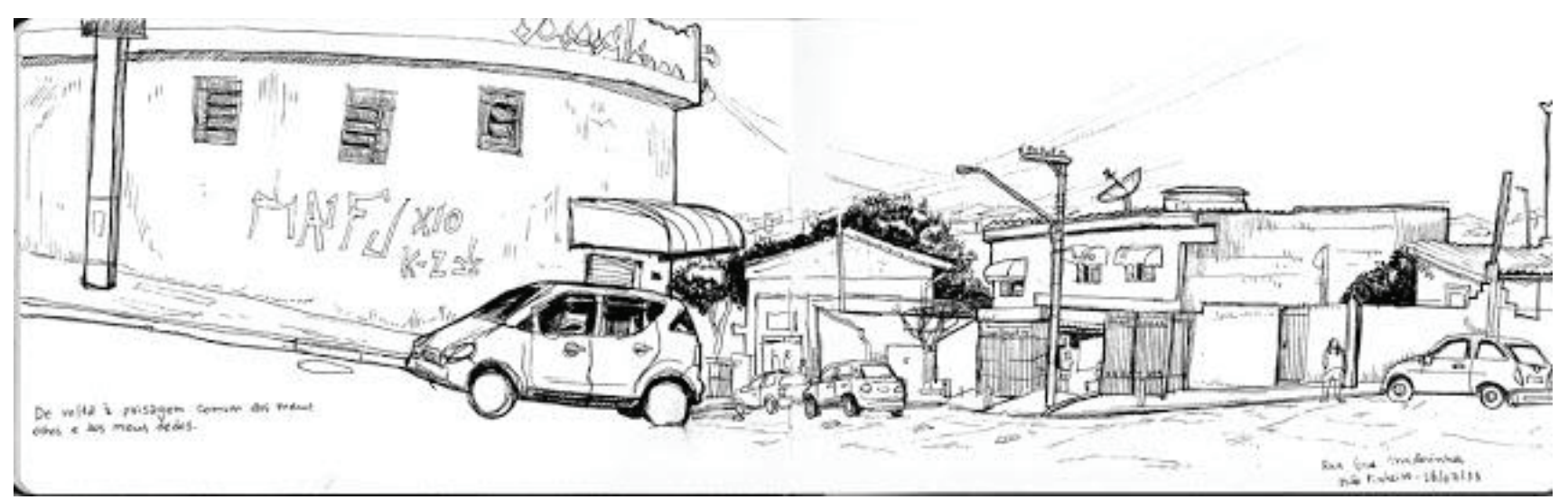

[Figura 2] Desenho de João Pinheiro na rua Erva Mularinha, em São Paulo. 2011.

Disponível em: <http://brasil.urbansketchers.org/2011/og/rua-erva-mularinha.html> Acesso em 14 mai. 2017. 
descubro detalhes despercebidos em minha própria cidade Mogi das Cruzes, e busco uma identidade nos meus traços, e sei com o tempo isso chega.

Ronaldo Kurita ${ }^{18}$ escreve que só conheceu São Paulo de verdade explorando-a para os trabaIhos universitários de urbanismo e que sempre se surpreende, até hoje, a cada nova descoberta. Regina Borba ${ }^{19}$, ao ouvir falar do USk, ficou encantada, questionando se porque não deveria desenhar sua cidade de São Luís, que é um patrimônio cultural da humanidade. Ao iniciar no movimento, ela acabou se apaixonando "por esse exercício e descobrindo cada cantinho especial" da capital maranhense. André Duarte Baptista ${ }^{20}$ afirma que uma das coisas que the atrai no desenho de observação é a "necessidade" de relação entre desenhador/observador e o objeto/espaço, que ele chama de "eterno jogo de sedução". Ele relata que sua dissertação de mestrado sobre o centro histórico de Torres Vedras possibilitou conhecer o desconhecido, e que "desenhar obriga-nos a perceber como se compõem e estruturam os elementos que nos rodeiam". O jogo de sedução citado pelo autor ultrapassa a relação observador-objeto e torna-se "um triângulo amoroso bastante interessante: observador/ objetos/ público". Ele finaliza escrevendo que desenhar tem tornado-o mais rico, observador e sensível à relação homem/espaço.

Em 2012, Gabi Campanario lançou um livro com relatos, desenhos e dicas sobre o universo USk. Os relatos do livro convergem para essas ideias de que o desenho possibilita descobertas visuais. A russa Olga Prudnikova testemunha a mudança de percepção sobre sua cidade, Moscou, pois acredita que deve-se "olhar com os olhos de um viajante". Apesar de começar a fazer sketches enquanto viajava, ela tomou a mesma atitude para seu dia a dia: "eu descobri que eu posso olhar para minha cidade natal, Moscou, com olhos diferentes" ${ }^{21}$, pois isso ajuda a perceber mais o seu derredor. Sua conterrânea, Zhenia Vasiliev, sublinha: "quando você desenha, você força a si mesmo a estar atento aos detalhes e começa a perceber quão pouco você conhece os locais familiares: as ruas que você caminha todos os dias, os ônibus que você toma ou a cafeteria onde você bebe um rápido café" 22 . A italiana Simonetta Cappecchi destaca essas relações com a cidade: "desenhar significa ficar mais tempo nos lugares, e isso sempre faz a diferença na forma como eu percebo coisas ou situações, nós entendemo-las melhor"²3. Para o equatoriano Omar Jaramillo, "desenhar é uma

\footnotetext{
18 KURITA, 2015

19 BORBA, 2012

20 BAPTISTA, 2015

21 "[...] I found that I can even look at my hometown, Moscow, with different eyes" (apud CAMPANARIO, 2012, p. 174).

22 "When you sketch, you force yourself to be attentive to the details and start noticing how little you actually know of familiar places: the street you walk down every day, the bus you're riding, or the café where you have a quick coffee." (Apud CAMPANARIO, (2012, p. 172)

23 "Drawing means staying longer in places, and this always makes a difference in the way we perceive things or situations, we understand
} 
forma de aprender por que um lugar é do jeito que é e o que o faz diferente de outros. É uma forma de amar um lugar, tornar-se parte dele"24. Ao incentivar o urban sketching, Campanario afirma que "suas habilidades ficarão afiadas e você ganhará uma nova apreciação do seu derredor"25. O marroquino Stuart Kerr e o estadunidense Matt Jones afirmam, respectivamente, que desenhar é "uma forma efetiva de conhecer adequadamente os lugares" ${ }^{26}$ e que ajuda a se familiarizar com um local, construir mapas mentais e aprender nomes de ruas e pontos de referência. Para Danielle McManus, de Nova lorque, sair para desenhar é adquirir um novo par de olhos, assim como para a dinamarquesa Ea Ejersbo, que diz: "fazer sketches faz-me desacelerar e olhar aquelas coisas que de outra forma eu não faria"27. O canadense Jerry Waese afirma que vê "as coisas de forma diferente" e encontra "motivos e belos ritmos no comum" enquanto procura por "pistas para composição no fluxo dos tráfegos"28. O espanhol Luis Ruiz olha sempre para cima, buscando "descobrir detalhes não percebidos nas fachadas e cornijas"29. "Fazer sketches é a única forma de contar estórias enquanto eu descubro o mundo", diz Paul Wang, de Hong Kong ${ }^{30}$. Wil Freeborn, de Glasgow ${ }^{31}$, afirma que fazer sketches "tem sido uma grande forma de explorar e descobrir mais sobre onde eu vivo". Por fim, para Rob Carey, da Alemanha,

Fazer urban sketches me força a sentar e realmente olhar para os detalhes que eu não perceberia normalmente. Eu me tornei isolado, porém muito conectado com meu ambiente, ao mesmo tempo. Embora relaxante, eu também acho isso incrivelmente desafiador. Quando você está fazendo sketches, você está encarando uma cena complexa de linhas intersectadas e formas incomuns e descobrindo como gravá-las no papel. A meta é transmitir sua experiência naquele momento com quem quer que veja seu sketch depois. É o mesmo que contar uma história. ${ }^{32}$

Simon Taylor ${ }^{33}$, em viagem à Buenos Aires (imagem 3), relata:

them better." (Apud CAMPANARIO, 2012, p. 202)

24 "Drawing is a way to learn why a place is the way it is and what makes it different from others. It's a way to love a place, to become part of it"(Apud CAMPANARIO, 2012, p. 214)

25 "(...) your skills will be sharper, and you'll gain a new appreciation for your surroundings" (2012, p. 18)

26 "Sketching was an effective way to meet locals properly" (Apud CAMPANARIO, 2012, p. 12)

27 "Sketching makes me slow down and see these things in a way I otherwise wouldn't" (Apud CAMPANARIO, 2012, p. 167)

28 " [...] I do see things differently; I find motif and beautiful rhythm in the mundane, and I look for composition clues in the flux of passing traffic" (Apud CAMPANARIO, 2012, p. 62).

29 "I am always looking upward, and I really enjoy discovering unnoticed details on façades or cornices." (Apud CAMPANARIO, 2012, p. 112)

30 "Sketching is a unique way of telling stories as I discover the world"(Apud CAMPANARIO, 2012, p. 234).

31 "It's been a great way to explore and find out more about where I live" (Apud CAMPANARIO, 2012, p. 164).

32 "Urban sketching forces me to sit and really look at details I wouldn't normally notice. I become detached, yet very connected with my environment at the same time. Although it's relaxing, I also find it incredibly challenging. When you're sketching, you're staring at a complex scene of intersecting lines and unusual shapes and figuring out how to record them on paper. The goal is communicating your experience at that time with whoever sees the sketch later. It's the same as telling a story". Apud CAMPANARIO, 2012, p. 186).

33 TAYLOR, 2015 
No único dia da viagem em que choveu, aproveitei para fazer um desenho da janela do hotel. Tudo corria bem até eu perceber uma casinha de dois andares, bem no topo de um prédio imenso. Sensação indescritível! A arquitetura da casa não tinha nada a ver com a do edifício. Era como se, num passe de mágica, a construção tivesse sido teletransportada [...] de uma paisagem rural européia para os píncaros da América do Sul [...].

Raro de Oliveira desenha uma casa no bairro Hugo Lange durante o $76^{\circ}$ Encontro do USK Curitiba. Oliveira dá detalhes sobre a produção:

A casa tinha sua elegância, mas a fachada lateral foi que me seduziu. Costo de tentar capturar essas pequenas revelações que só se mostram quando a gente está buscando o que desenhar. Do outro lado da rua uma flor entreaberta também merecia um registro. A flor entreaberta e a fachada escondida travavam uma conversa inaudível... quem sabe o desenho possa revelar um pouco desses segredos.

Dalton de Luca ${ }^{34}$ confessa que ao fazer desenhos no Pátio do Colégio, em São Paulo, nunca tinha prestado muita atenção na coluna chamada "Clória Imortal aos Fundadores de São Paulo", do escultor italiano Amedeo Zani. Eduardo Lott ${ }^{35}$, do Rio de Janeiro, desenha uma cena de rua e percebe uma árvore no telhado. Thaís Machado ${ }^{36}$ relata um dia em que foi à Escadaria Selarón, que liga a Lapa à Santa Teresa, no Rio de Janeiro: "lá uma grande quantidade de turistas já se encontravam presentes, tirando muitas fotos, selfies e procurando entre os milhares de azulejos os de suas terras natais. A surpresa, o encantamento e a felicidade eram contagiantes", diz ela, que também relata a dificuldade de desenhar o local: "[...] descobri que a perspectiva era bem mais complexa do que imaginei", pois havia muita gente circulando e a "escadaria tem diversos trechos e patamares, que não são regulares, o que só descobri enquanto desenhava" Marília Varella ${ }^{37}$ faz um registro de uma escultura que não conhecia no Museu Oscar Niemeyer, na área externa. Adriana Dantas afirma ${ }^{38}$ :

Sempre gostei de representar o que vejo, acredito que seja um meio de registro do tempo que não volta mais e de maior proximidade entre o observador e a coisa observada. Tenho dito aos que querem aprender a desenhar, parafraseando o grande desenhista e professor Kimon Nicolaides, que dizia: 'Desenhar é uma questão de aprender a ver'. Ou seja, um bom artista não é aquele que "sabe desenhar", mas aquele que sabe ver. Por isso tenho creditado os desenhos a uma boa observação. Os olhos que apreendem as formas, as cores, os detalhes, devem ser o ponto inicial para um investimento no ato de desenhar.

\footnotetext{
LUCA, 2011

<https://www.facebook.com/photo.php?fbid=384424755244939\&set=gm.1184233478363146\&type=3>Acesso em: 01 maio 2017 .

36 MACHADO, 2015

37 <https://www.facebook.com/photo.php?fbid=1079888728728779\&set=gm.927644430688720\&type=3>Acesso em: 01 maio 2017.

38 DANTAS, 2016, grifos da autora
} 


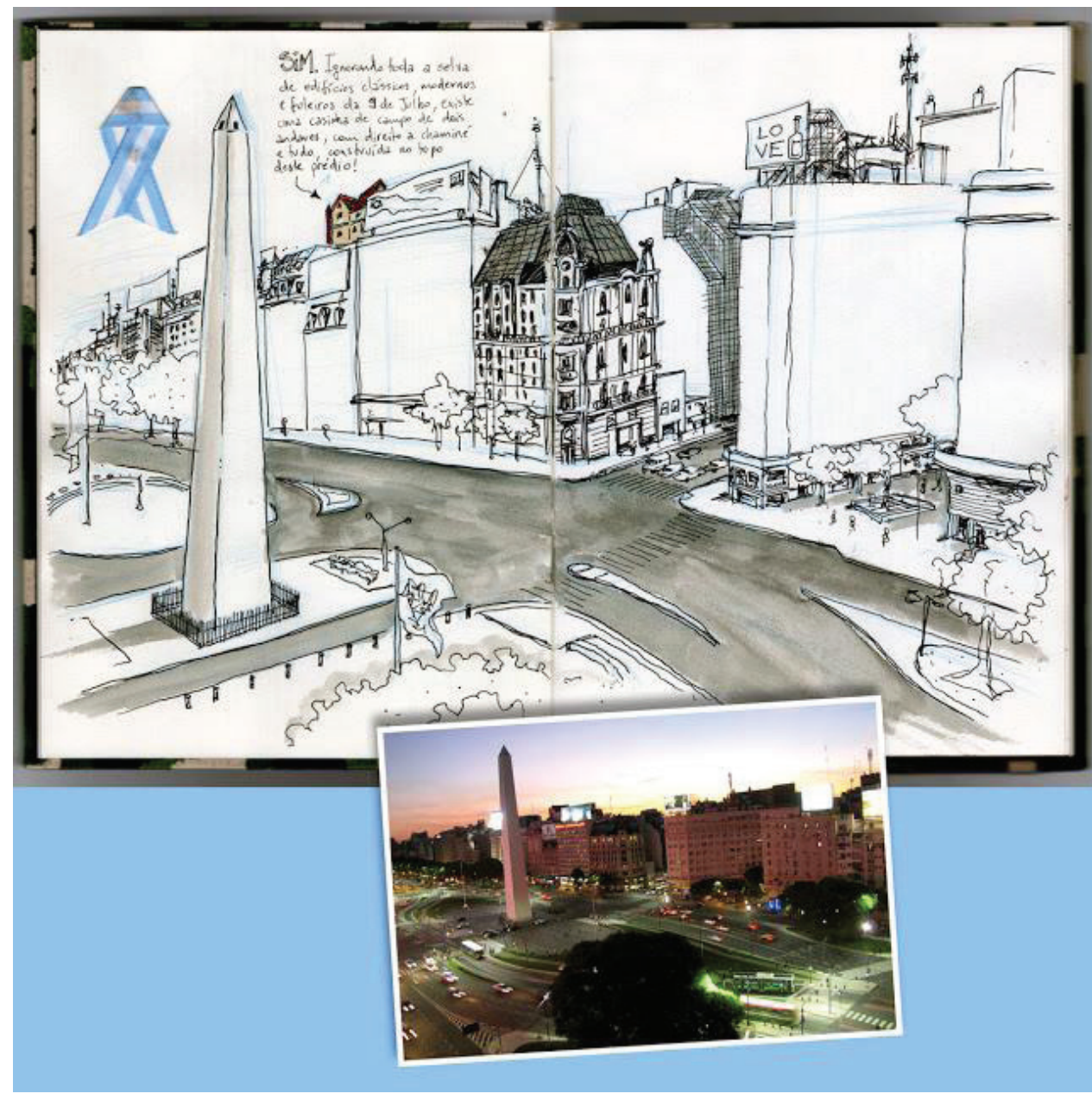

[Figura 3]

Recorte de desenho de Simon Taylor em Buenos Aires. 2015.

Disponível em: <http://brasil.urbansketchers.org/2015/07/diariode-viagem-3-buenos-aires.html> Acesso em: 16 mai. 2017

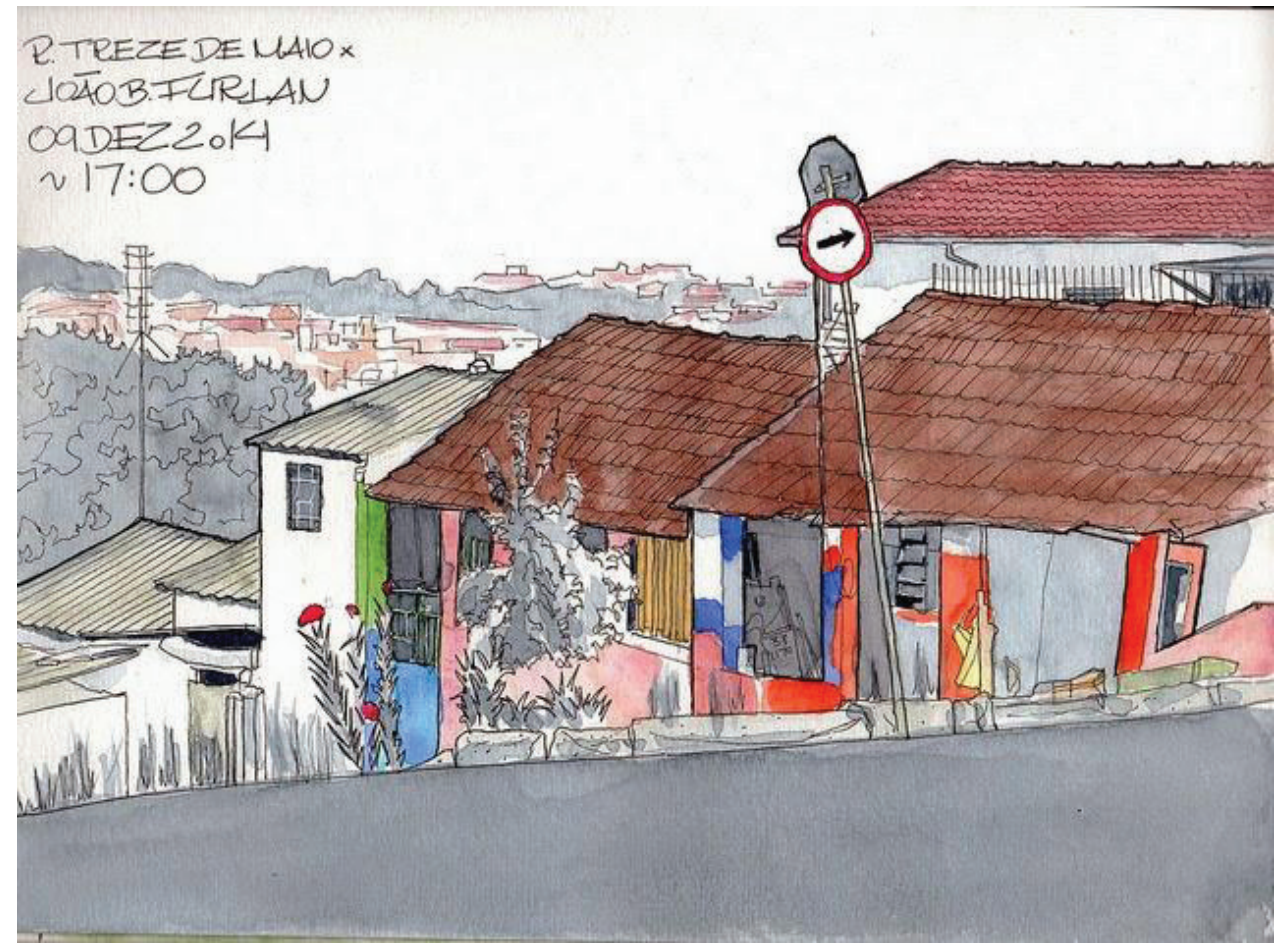

[Figura 4]

Desenho de Flávio Ricardo em Santa Bárbara d'OesteSP. 2015.

Disponível em: <http://brasil. urbansketchers.org/2015/01/ferias-em-santa-barbara-doeste-sp. html> Acesso em: 14 maio 2017. 
E, complementando com Maurice Crosser : 'O pintor pinta com os olhos, não com as mãos'.

No relato de alguns desenhos, Flávio Ricardo ${ }^{39}$ destaca a descoberta de "um pequeno beco, bloqueando com elementos de aço a passagem de motocicletas" e as muitas pessoas que utilizaram este beco como passagem. Em outro momento (imagem 4), ele relata ${ }^{40}$ :

Durante as últimas semanas de dezembro estive em férias, que passei na casa dos meus pais, em Santa Bárbara d'Oeste. Nesse tempo procurei, através do desenho, redescobrir a cidade onde passei minha infância e adolescência. O olhar viciado, acostumado a procurar e a encontrar tudo aquilo que penso saber da cidade, sempre me dizia que nela não há nada de interessante. Aqui vão alguns dos registros dessa minha busca. Esta é da parte mais antiga da cidade. Zona limítrofe, são as ruas finais da parte central. A declividade acentuada vem da proximidade com a várzea de um rio. A demolição de um muro nesta esquina revelou a intimidade até então escondida nesta edificação cujo uso não consigo identificar (uni ou multifamiliar?).

Ele descreve ainda outros locais: esta mesma rua que termina em uma curva, um "interessante conjunto de casas", o encontro de duas avenidas que margeiam a ferrovia, uma curva "extremamente acentuada", um semáforo, um muro grafitado por um artista desconhecido, um carrinho de lanches e um antigo caminhão sempre em frente à casa do proprietário, que "parece já fazer parte da rua". O sketcher afirma que colocar em evidência aquilo que passa desapercebido é uma das qualidades da atividade de desenhar" e que "as trocas, o trabalho, o espaço público e sua apropriação, o conceito do abrigo, seja ele uma árvore ou a lona de um carrinho de lanches" Ihes vieram à mente após estes desenhos: "não sei dizer bem o porquê da escolha do objeto. Talvez estas ideias já estivessem latentes, esperando que fossem desenhadas".

Essa frase de Ricardo é muito interessante para se pensar sobre o olhar e o desenho, e como estas coisas "já latentes" despertam aos olhos dos sketchers. Guto Lacaz ${ }^{41}$ diz que "uma pessoa só pode dizer que viu uma coisa, depois de tê-la desenhado". Podemos pensar que a cidade e o que está nela quer ser desenhado, espera por isso, por sua descoberta. John Berger ${ }^{42}$ já afirmava que para o artista, "o desenho é descoberta", sendo isso literalmente verdade: "é o próprio ato de desenhar que obriga o artista a olhar para o objeto à sua frente, a dissecá-lo em seu olho mental e juntá-lo novamente". É pelo desenho que se descobre a cidade, que se desvenda seu cotidiano, que

\footnotetext{
39 RICARDO, 2015b

40 RICARDO, 2015a

41 LACAZ apud DERDYK, 2007, p. 261

42 BERGER, 2005, p. 3
} 
se desvelam seus citadinos.

O Urban Sketchers é, então, apresentado como um movimento que destaca as potencialidades do desenho, levando-nos a conhecer os espaços com mais afinidade, registrar a nossa própria trajetória de vida, os lugares onde vivemos e para onde viajamos, enfim, desenhar enquanto se olha e assim, aprender a ver melhor.

\section{Referências bibliográficas}

BAPTISTA, André D. Conheça os Correspondentes: André Duarte Baptista, de Torres Vedras (Portugal). Urban Sketchers Brasil. 2015. Disponível em: <http://brasil.urbansketchers.org/2015/og/conheca-os-correspondentesandre-duarte.html> Acesso em: 31 out. 2016.

BERCER, John. Draw to that moment. In: SAVACE, Jim (org.). Berger on drawing - essays. Cork: Ireland Occasional Press, 2005. Disponível em: <http://www.spokesmanbooks.com/Spokesman/PDF/90Berger.pdf> Acesso em: 30 out. 2016. 
BORBA, Regina. Conheça os Correspondentes: São Luís - Maranhão < Regina Borba. Urban Sketchers Brasil. 2012. Disponível em: <http://brasil.urbansketchers.org/2012/12/conheca-os-correspondentes-sao-luis.html> Acesso em: 28 out. 2016.

CAMPANARIO, Gabriel. The art of Urban Sketchers: drawing on location around the world. Quarry Books: Beverly, 2012.

DANTAS, Adriana. Conheça os Correspondentes: Adriana Dantas, de Aracajú-SE. Urban Sketchers Brasil. 2016. Disponível em: <http://brasil.urbansketchers.org/2016/08/conheca-os-correspondentes-adriana.html> Acesso em: 05 jul. 2017.

DERDYK, Edith (org). Disegno. Desenho. Desígnio. São Paulo: Editora Senac São Paulo, 2007.

EÇA, Teresa Torres. Desígnios do Desenho no contexto da cultura visual. Educação \& Linguagem. v. 13. n. 22. p. 153168, jul.-dez. 2010.

CORDO, A.; PADRON, L.;RODRICUEZ, F. Aprendiendo de los urban sketchers: el tiempo en el dibujo. El dibujo de viaje de los arquitectos : 15 Congreso Internacional de Expresión Gráfica Arquitectónica, Las Palmas de Gran Canaria, del 22 al 23 de mayo de 2014. p. 87-94. Disponível em: <https://idus.us.es/xmlui/handle/11441/28245> Acesso em: 01 nov. 2016.

ISODA, Gil T. T. Sobre desenho. Estudo teórico e visual. Dissertação de mestrado.

KURITA, Ronaldo. Conheça os Correspondentes: Ronaldo Kurita, de São Paulo/SP. Urban Sketchers Brasil. 2015. Disponivel em:<http://brasil.urbansketchers.org/2015/05/ronaldokurita.html> Acesso em: 28 out. 2016.

LUCA, Dalton de. $33^{\circ}$ Sketchcrawl! Solo. Urban Sketchers Brasil. 2011b. Disponível em: <http://brasil.urbansketchers. org/2011/10/33-sketchcrawl-solo.html> Acesso em: 05 jul. 2017.

MACHADO, Thais. Duas manhãs, dois temas, dois locais do subúrbio carioca. Urban Sketchers Brasil. 2015a. Disponível em: <http://brasil.urbansketchers.org/2015/01/duas-manhas-dois-temas-dois-locais-do.html> Acesso em: 30 out. 2016.

MELLO, Adriano. Largo do Carmo Mogi das Cruzes. Urban Sketchers Brasil. 2015. Disponível em: <http://brasil. urbansketchers.org/2015/08/largo-do-carmo-mogi-das-cruzes.html> Acesso em: 05 jul. 2017.

PETHERBRIDCE, Deanna. Nailing the liminal: the difficulties of defining drawing. In: CARNER, Steve. Writing on Drawing. Essays on Drawing Practice and Research. Intellect Books, 2008.

PINHEIRO, João. Rua Erva Mularinha. Urban Sketchers Brasil. 2011. Disponível em: <http://brasil.urbansketchers. org/2011/og/rua-erva-mularinha.html> Acesso em: 28 out. 2016.

RICARDO, Flávio. Férias em Santa Bárbara d'Oeste-SP. Urban Sketchers Brasil. 2015a. Disponível em: <http://brasil. urbansketchers.org/2015/01/ferias-em-santa-barbara-doeste-sp.html> Acesso em: 05 jul. 2017.

Espaços públicos e privados. Urban Sketchers Brasil. 2015b. Disponível em: < http://brasil. urbansketchers.org/2015/05/espacos-publicos-e-privados.html> Acesso em: 04 jul. 2017.

SALAVISA, Eduardo (org.). Diários gráficos em Almada - "Não somos desenhadores perfeitos". Almada: Câmara Municipal/Museu da Cidade, 20.

SOARES, Rute M. L. O Lugar do Olhar: desenho, arte, composição e imaginação. Relatório de Prática de Ensino supervisionada. Mestrado em Ensino das Artes Visuais. Universidade de Lisboa, 2015. Disponível em: <http://repositorio. ul.pt/handle/10451/23390> Acesso em: 07 jul. 2017.

TAVARES, Carla. $O$ desenho à maneira dos mestres como metalinguagem. Relatório da prática de ensino supervisionada. Mestrado em ensino de Artes Visuais. Universidade de Lisboa, 2011.

TAYLOR, Simon. Diário de viagem \#3 - Buenos Aires. Urban Sketchers Brasil. 2015b. Disponível em: <http://brasil. urbansketchers.org/2015/07/diario-de-viagem-3-buenos-aires.html> Acesso em: 05 jul. 2017.

VALERY. Paul. Degas dança desenho: Paul Valery. Trad. Christina Murachco e Célia Euvaldo. 1 ed. São Paulo: Cosac Naify, 2012. 